\title{
Li-Young Lee’s “I” Poetry: In Quest for His Self as a Diaspora
}

\author{
LI Gui-cang \\ Zhejiang Normal University, Jinhua, China
}

\begin{abstract}
As one of the representative contemporary Asian American poets, Li-Young Lee in his two poetry collections entitled Rose and The City in Which I Love You, recuperates his fragmented family history of immigration, and reconstructs a dynamic relationship with remembrance of the past that writes about him and defines his sense of self. This paper from the multicultural perspective argues that understanding the past through understanding his godlike father, Lee not only negotiates the formation of his subjectivity and identity, but also establishes a spiritual origin and belonging not merely with his ethnic communities but with all the immigrants as well. The paper finds that the strategy he employs in his articulation of his self is marked by his excellent execution of poetic epiphany, and metonymic cannibalism.
\end{abstract}

Keywords: Li-Young Li, sense of self, Asian diaspora, poetic epiphany, metonymic cannibalism

\section{Introduction}

Juliana Chang (1999) in her award winning essay Reading Asian American Poetry identifies two dominant critical perceptions of reading this body of works. The first is to practice what she considers a "privatization of poetry, which would imply taking [the ethnic poetry] more lightly than prose narrative”, whereas the second "conceive[s] of poetry as heavily social” (p. 85). The privatization reading is further enunciated as a critical assessment of poetry as "a private and subjective luxury in the context of current multiculturalism" (p. 86). In contrast, the socialized reading is said to "extol poetry as a direct and powerful embodiment of the social or historical” (p. 86). Chang critiques these two dominant approaches to this body of works and asserts that "whether poetry is perceived as erasing or creating racial and cultural differences, the [two] readings are in fact inflected with and serve to maintain dominant ideologies of language and writing, race and nation” (p. 89). In other words, whether critics privatize or politicize poetry, their critical preference reflects the mainstream cultural ideology. As regards the critical perspectives, the two approaches as she identifies may loosely apply to Asian American poetry as a whole, but critical readings of individual poets have to alter in alignment to the unique qualities of their poems, because poetry criticism cannot be generally subsumed under the logic of either privatization or politicization. Specifically, not all criticisms are adequate and productive in reading Asian American poetry, for particular poems are intended to be interpreted particularly. For instance, contemporary Chinese American poet Li-Young Lee presents his persona in Rose (1986) and The City in Which I Love You (1990) as an Asian diaspora, who maneuvers across the interstices of diverse cultures, histories, discourses, and poetic traditions in search of his identity as a diaspora; hence an obvious choice here to discuss his poetry that, to

Li Gui-cang, professor, Dean, College of International Culture and Education, Zhejiang Normal University. 
borrow Homi Bhabha's words in Location of Culture (1997), addresses "a cultural politics of diaspora and paranoia, of migration and discrimination, of anxiety and appropriation” (p. 59). To be noted that Lee's poems are overtly "personal", they do not demand a privatization reading, simply because the core of his "cultural politics of diaspora" constitutes a relentless quest for whom he is in relation to his self consciousness, histories, memory, and the depth of his character as a diaspora. The author will focus on his rhetorical delineation of his subjectivity in the context of cultural politics that articulates historical, familial, racial, and geopolitical issues in the hope to understand his multivalent sense of self as results from his lived experience of a diaspora.

After briefly discussing the identity question addressed in Li-Young Lee's poetry, Yu (2000) in his Form and Identity in Language Poetry and Asian American Poetry claims that Lee's work is rooted "in a coherent, physical self", and "grapples with the self all the time" (p. 447). Yu indicates that the thematic content and formal choice of Lee's poetry are mainly constituted of representations of that "coherent self". This paper argues that the quest, delineation, examination, and interrogation of his complex and dynamic self as a Chinese diaspora are what render Lee's poetry the most self-exploratory, and in a sense, special in contemporary Asian American poetry.

Hardly can one find a Descartes' sense of a "coherent self” in Lee’s poetry. Rather, a casual glimpse of Li-Young Lee's poetry would even impress readers that questions of "I" and the construction of subjectivity are particularly complex and central to his work. De facto, the imminence in Lee's poetry is his undertaking of a herculean effort in articulating and constructing his subjectivity and cultural identity by making sense of his and his family's particularity in transnational geopolitics.

Of all the Chinese American poets, Lee is likely the only one who fuses subjectivity and family history in such a manner that the self, as manifest in most of his poems, is maintained and revised by the past and other factors in his life. Apparent in his poetry is a surging desire always at play to reconstitute through "constant remembrance" his fragmented life into an emotional quest for subjectivity and cultural identity (Lee, 1990, p. 14). He defines and redefines his subjectivity by writing and rewriting about his and his family's past, which represents loss, meaninglessness, political persecution, personal tragedy, disconnection, and dislocation. The nature of what he constructs and negotiates is as Bhabha (1997) states in Location of Culture that "[i]t is in the emergence of the interstices - the overlap and displacement of domains of difference - that the intersubjective and collective experiences of nationness, community interest, or cultural value are negotiated” (p. 2). Bhabha points out here that subjectivity and cultural identity cannot be ascribed to pre-given, irreducible, prescriptive, coherent, scripted, and ahistorical individual and cultural traits that define the conventions of ethnicity. On the reverse, "subjectivity" is an entity that is fluid, rather than "coherent", and constantly changing along with other social, political, and cultural factors: It is historical, and as well as cultural, as is apparent in Lee’s poetry.

To Lee, "historical” here refers to familial and personal history, hence memory and past remain seminal in his construction of subjectivity as manifested by his inexhaustible effort in constructing a dynamic relationship with his father and the other members of his family through "constant remembrance”, because, as he understands it, "Memory revises" him (1990, p. 14). He never writes about the past as a way to escape the present and future. Rather, he firmly believes that the meaning of "what I am" depends solely on the incorporation of the past into his everyday life. It is the past, or the past related with his father, that defines his true self. In a sense, the past is not what he writes about. Rather, it is the past that writes about him. Since his father represents all the meaning of the past to Lee, understanding the god-like man foregrounds his reconstruction of self: his attempt to understand his 
father takes three forms: philosophical meditation, poetic epiphany, and cannibalism. Through remembrance he reconstitutes his family's past, which serves as a force to strengthen his subjectivity and identity, and a source of his personal integrity, values, emotional and intellectual power as a Chinese diaspora in the United States.

\section{Philosophical Meditation: Spirituality and Subjectivity}

Chinese American poetry, like any other ethnic literature in the United States, is mainly concerned with the search and reconstitution of subjectivity and identity. In his foreword to Li-Young Lee's Rose, Gerald Stern (1986) characterizes Lee’s poetry as "a pursuit of certain Chinese ideas, or Chinese memories... and a moving personal search for redemption" (p. 9). Stern does not outline what those "ideas" entail, and nor does he underpin what that "personal search for redemption" designates. A more convincing argument would be that Lee searches for the meaning of self in the context of the loss of self, disconnection, fragmentation, and the ever present anxiety over the loss of spirituality as the result of his life as a Chinese diaspora, and, of man's obsession with materialism in general.

Like most modern masters of poetry, Lee is concerned with spirituality in relation to his subjectivity. In this sense, he is in philosophy more leaning to the Hegelian in this regard. Lee acknowledges Eliot's influence on him in his interview with Tod Marshall. Lee believes Eliot's lifelong concern with modern man's inadequacy, ineffectualness, and spiritual futility through his overt contrast of the grandeur of the past with the sordidness of the present as evident in The Waste Land, influences Lee so much that he is totally committed to his poetic preoccupation with his own spirituality as an immigrant, and spirituality of life in general. He despises poetry represented by William Carlos Williams, accusing it of being "so concerned with apparent materiality" (Marshall, 2000, p. 133). Like Eliot, Neruda, and Tu Fu, Lee delineates the condition of man's spirituality. Look at his version of The Waste Land, where materiality is shrouded in death:

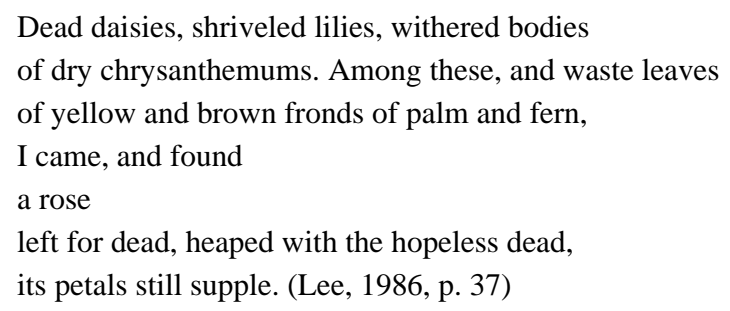

Yet, unlike Eliot, Lee seldom displays Eliot's cynicism about human spiritual retrogression: The rose survives among the "hopeless dead". In this respect, Lee resembles Tu Fu, whose unsurpassed representation of the miserable fate of the ordinary people serves almost as an unlimited source of inspiration for all the poets of the Chinese language or heritage. Like $\mathrm{Tu} F u$, Lee believes that human spiritual degradation partially results from man's placing too much significance on materialism and the selfish pursuit of power and status. Lee approaches spirituality by the denial of any significance of materiality at all, as is footnoted in his assertion that "[T]he true self is the one that speaks, and it does not give a damn about the one that walks in clothes. The rest is Chaff" (Marshall, p. 135). In other words, spiritual gain and perfection can only be accomplished through denial of the physical. Such a position may sound a little extreme but understandable if we know all the ordeals his family has undergone: Spiritual tenacity is what invigorated them to live on; material possessions would have been necessary but not essential in their struggle for a more meaningful survival and life. 
The seemingly overt emphasis on spirituality reflects Lee's concept of the relation between spirituality and subjectivity. To him true subjectivity can only be negotiated through the understanding and pursuit of man's spirituality: "It is the exercise of the mind to think constantly that this false identity (all the things in the room) is fading away” (Marshall, p. 134). Lee believes in the possibility that through logos or Tao or God, man can articulate his true self. Most of Lee's poetry attests to his unyielding belief in the shaping power of spirituality in his search for meaning. Even in his many references to the body of his father, the material/physical substance gradually disappears. In its place emerges the inexhaustible search for spirit and soul. An interesting illustration of how the material aspect evaporates and the spiritual sustains is found in the title poem The City in Which I Love You (Lee, 1990):

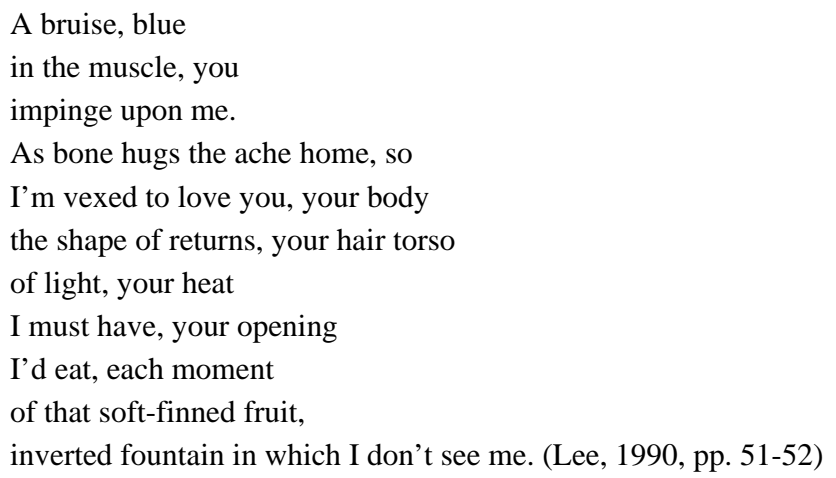

Only the spiritual sustains. And the material merely functions as an avenue toward the spiritual. Again, the negation of the material seeks to reveal a possible fullness and fulfillment of human spirituality.

An interplay of spirituality and remembrance is captured in the following lines about his acute sense of disconnection and dislocations:

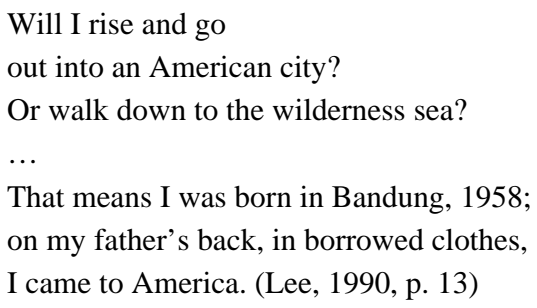

A similar significance of remembrance in the construction of his subjectivity and identity is unmasked in Bhabha’s Remembering Fanon. Bhabha (1994) contends that

Remembering [...] is a process of intense discovery and disorientation. Remembering is never a quiet act of introspection or retrospection. It is a painful re-membering, a putting together of the dismembered past to make sense of the trauma of the present. (Bhabha, 1994, p. 121)

Given that, but how can the remembrance of the past revise Lee in particular? The philosophical emphasis on the shaping abilities of the past and reminiscence is well elucidated in Lee's own explanation of the Chinese notions of what the past, present, and future are:

The Chinese word for the day after tomorrow is hou, meaning behind, and the word denoting the day before yesterday is actually chien, meaning in front of. So, you see, Tod, that to a Chinese mind, tomorrow, the future, is behind 
me, while the past lies in front of me. Therefore, we go backing up into the future, into the unknown... and everything that lies before our eyes is past, over already. (Marshall, 2000, p. 133)

He then uses the stars as an analogy to illustrate his point that what we see is done, over with, gone, or even dead long ago. In other words, the present, as well as the future is illuminated and enunciated by the understanding of the past. Such an epistemology of the relationship between the past and future demands a constant return to the past in order to understand the present and the future, or "the unknown", as Lee calls it elsewhere in the interview.

\section{Poetic Epiphany in Understanding His Father}

The remembrance of past experience facilitates an access to knowing his father in order for Lee to define his subjectivity through an epiphany. In the sixth section of Rose, Lee recollects one of his visits to his father's house, which is almost buried in rotten fruit and wild grass. He stands in the desolate yard "not for the scent/of their dying.../Not for the wild grass/grown wild as his beard in his last months/not for the hard, little apples that littered the yard" (Lee, 1986, p. 42). And then, "The rain came. And where there is rain/there is time, and memory, and sometimes sweetness" (p. 42). As the rain enlivens everything, and brings back a sweet memory of his father, he realizes that "Where there is a son there is a father" (p. 42). The sudden remembrance of his father reduces to triviality his purpose of presenting himself physically in front of his sick father. The visit loses its significance of seeing the dying man and re-orients in the revelation of the man's spirituality. If the initial purpose is to see his father, the remembrance provides access to the understanding of his father and the spiritual connection between them as father and son. Furthermore, the evocation of his father transforms the speaker into a new persona, who is now able to overlook the devastating scene and sees something inspirational, which is ablaze yonder:

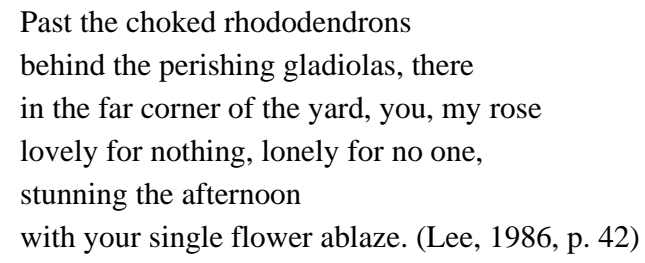

Because of the remembrance of his father, the simple, routine visit is completed with his letting "the rain/meditate on the brilliance of one blossom/quivering in the beginning downpour" (p. 42). The "brilliance of one blossom" symbolizes the spiritual power he associates with his father. The epiphany brings him closer to his father spiritually, if not physically. Happy, reflective, and content, he leaves without seeing his father. At this point, seeing is replaced with understanding. What a thorough transmutation of the one who first stands in the desolate yard, disconcerted, uncertain, troubled, and preoccupied! The awareness of the sustaining power of spirituality as embodied in the glowing flower enables him to identify completely with his father. Spiritual communion overrides the necessity of seeing his father. His visit to his then blind father turns out to be a rediscovery of himself and his father.

Lee's poetic recuperation of the diasporic history of his family and his desire to know his father in order to be able to identify with his father indicates that his concept of self is largely influenced by Chinese culture and philosophy. He seems to have accepted the Confucian philosophy of the relationship between the self and society. 
Generally speaking, Chinese people tend to see themselves first as family, kindred, and social members, and second as discrete individual beings. There is no ambiguity that they so reserve themselves as not to be fantastic individuals, but their sense of self is more defined in relation to others. Their pursuit of self seldom purports to set themselves essentially apart from the society as remarkable individuals only. Rather, it is a continuous effort in becoming more fully accepted into a group, a clan, and, ultimately, into the society that defines how and why they strive.

Lee told Marshall, "Somehow, an artist has to discover a dialogue that is so essential to his being, to his self, that it is no longer cultural or canonical, but a dialogue with the truest self. His most naked spirit” (Marshall, 2000, p. 132). Memory serves as the medium of creating and maintaining such a constructive dialogue, through which he builds a relationship with the past, hence his reconstruction of his subjectivity. Such a concept of the self requires that the individual essentially situate his self in a filiative order-a concept that demands incorporation of family history or national history to negotiate individual subjectivity. Although accepting such an order as necessary to define his self, Lee's life in exile disallows him to situate completely the self in relation with any of the histories of China, Indonesia, Hong Kong, Japan, or America, or with any particular place where Lee has spent some time in his life. The only history available to him is history on a personal level. It is personal history only that matters and speaks to him. Since he has lived a raveled skein of life first as a refugee in many countries and later as an immigrant in the United States, the only significant filiations he can incorporate into the redefinition of his subjectivity to define the meaning of his true self is the turbulent history of his family, the center or the hero of which is his father.

In all his poetry, Lee tries to understand himself by understanding his father, a figure who appears as a generator of meaning of his life. In Rain Diary, Lee beautifully writes about his “search” for his father:

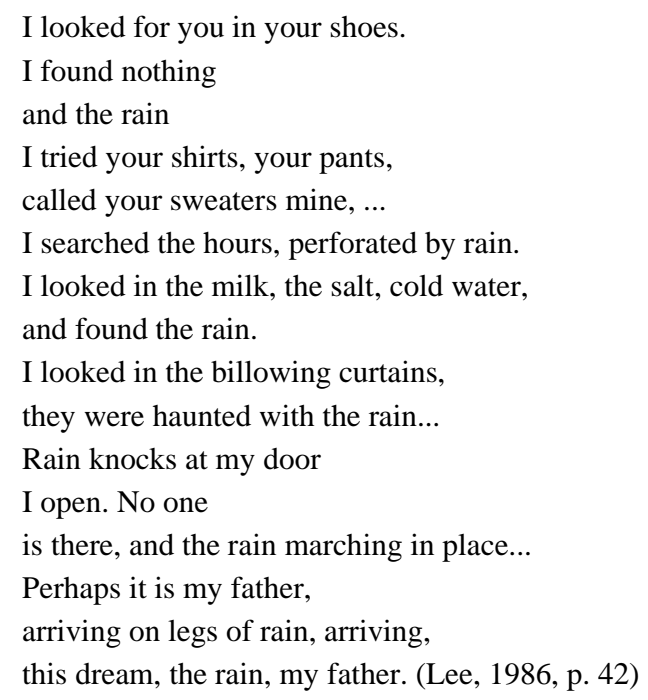

His childish but vigorous search ends in the soothing illusion that his father may come to him on the "legs of the rain”. Although he seems to be the source of Lee's being, the father is never presented as a fully developed character in Lee's poetry. He represents a victim of his times and international politics, a victim who has noble spirit and lets his hair grow "past his shoulder" (p. 60). Maybe that is the reason Stern sees the father as "an 
extraordinary and heroic" and a "mythic figure”, who "is more godlike” (p. 9). In Lee’s eyes, his father is godlike in terms of tribulations and of the magnitude of his spirit.

\section{Metonymic Cannibalism}

Indeed, Lee eulogizes his father as a godlike figure: "My father the Godly, he was the chosen/My father almighty, full of good fear" (Lee, 1986, p. 42). As we try to understand and embrace God in proper and manageable names, out of something that, as Confucius warns, improper nomenclatures obstruct communication, Lee thus asks his dead father:

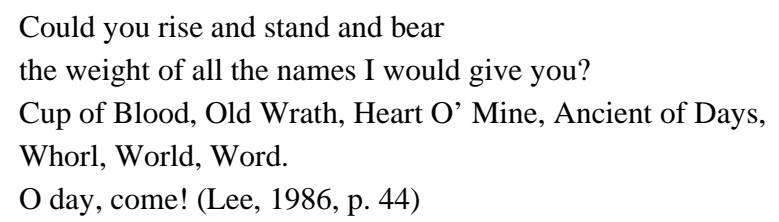

Giving different names designates his wish and desires to approach his father, who is like "The Old book I finished reading/I've since read again and again”, as well as his inability to completely understand the godlike man (Lee, 1986, p. 69). The surging desire of knowing the man like waves in the high Atlantic Ocean keeps charging at him. However, all his means-philosophic meditation, poetic epiphany, and sensibility-to comprehend the godlike man fail him; he turns to his last recourse—-the cannibal:

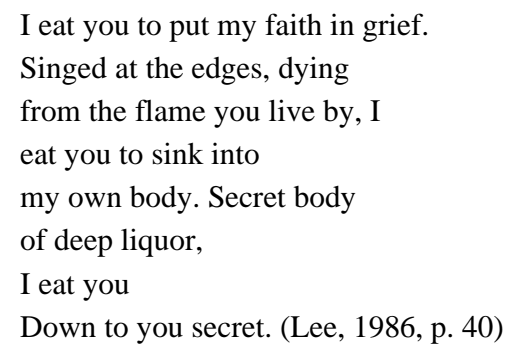

As the Holy Communion service satisfies people's wish to have God in themselves and as part of their life, so is the significance of Lee's cannibalism revealed here. Although the wish for a total physical possession of his father entails Lee's position of subjectivity as a single stable source of his feelings and intellectual power, indicating that the source is accessible, the source remains mythic and enigmatic anyway. As suggested earlier that Lee's disbelief in the value of materialism runs awry with his search for spirituality and subjectivity in the physical embracing of his father, Lee can only evoke the memory of his father's dead body. The "secret" is yet to be solved. He has to continue interrogating: "What are you to me/I'd tear you with my teeth" (Lee, 1986, p. 43).

The fact that his father no longer remains available exacerbates his frustration. What is left of his father is an "Excellent body of layers tightly/wound around nothing" (Lee, 1986, p. 40). The word "layers" not only denotes the layers of clothes on his father's corpse, but also delimits his full understanding of the man, who "exiled from one republic and daily defeated in another/who was shunned by brothers and stunned by God” (Lee, 1986, p. 41). As represented in all of his poetry, his father is never a heroic figure but a helpless and passive victim of geopolitics, who, like a boat adrift in the high seas, has no control of his fate at all, except for his firm belief in spirituality and final justice. But, how can Lee identify with such a pathetic victim? Why does Stern see the father 
as a "heroic figure?" What is there in this political victim that validates Stern's claim of "heroic" qualities?

The strategy Lee employs is to differentiate his father as a noble human being from his kinsmen without the need to present his father's tangible and recognizable heroic qualities. As a poet, Lee reveals them, out of a deep love and respect for his father, by contrasting his father to his kinsmen and fellow countrymen, who are presented as a contemptible race, cruel, bloodthirsty, and crazy:

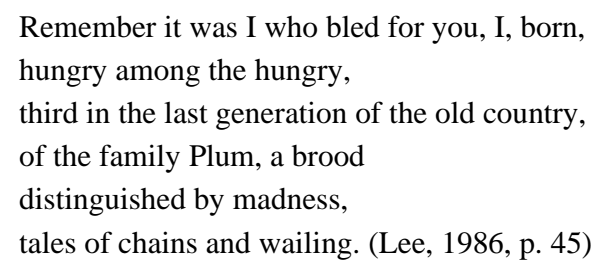

For Lee, not only are family history and the past the impetus to write about, they become what needs to be incorporated into his poetry, the very element needed to experience the self. Memory as a poetic form and structure provides access to the experience of his subjectivity and identity. It is through memory, though it fails him sometimes, that Lee bewares of the relationship between his self and his family, particularly his father, because memory, in Timothy Yu's words, has become "a necessary foundation for future action” (p. 447). In The Room and Everything in It, Lee claims that "of the one thing I learned/of all things my father tried to teach me/the art of memory" (Lee, 1990, p. 49). Through this form of art, he attempts to understand who he is by constantly articulating the particular relationship he has with his father until he realizes that he cannot separate his life from his father's: "Is this the first half of the century or the last/Is this my father's life or mine” (Lee, 1986, p. 52). And "among/the dying things/are you and I" (Lee, 1986, p. 45).

Through the art of memory Lee has constructed an image of his father: a godlike victim of political atrocity and his times, whose forbearance keeps him through the ungodly parlous times. In The Location of Culture Bhabha asserts that "the question of identification is never the affirmation of a pre-given identity, never a self-fulfilling prophecy - it is always the production of an image of identity and the transformation of the subject in assuming that image” (p. 45). If Lee succeeds in his deification of his father in his poetry, he totally assumes that image:

[M]y true self or identity is universe or God. There are certain assumptions that I secretly carry around, and I do not know if other poets share these. I assume that my true nature is God. I assume I am God, in my true nature. (Marshall, 2000, p. 134)

Some postmodern cultural critics would argue that the past is inaccessible and history only exists in texts, both of which are subject to interpretations. Yet, with Lee, history and the past are not only real on personal and emotional levels, but also, penetrable through the agenda of memory. As shown in his "Always a Rose”, "history resembles flowers”, “where/a world of forms convulses” (Lee, 1986, p. 20). Lee proclaims:

I see these flowers, and they seize

my mind, and I

can no more unsee

them than I can undream

this, no more than

the mind can stop 
its wandering over the things

of the world, snagged on the world

as it is.

The mind is

a flowering

cut in time,

a rose,

The wandering rose. (Lee, 1986, p. 20)

To Lee, history seems to be something wherein the self can ground itself. History takes different forms, and therefore, generates different meanings the way we make associations with flowers in the mind. Lee believes that history, especially the personal and family, provides the foundation for the construction of subjectivity, which never retains its wholeness, but remains in constant revisable permutation. In this sense, Lee's poetic articulation of self is in tune to what Nietzsche and Foucault examined the concept of subjectivity, because they believe that "there is no final evidence for the existence of the 'I' as a stable substance or essence" (Cavallaro, 2001, p. 89). To Lee and to them, subjectivity can only be approached and addressed through discourses for which remembrance serves as a structural means, hence Lee asserts that his self is under "ceaseless invention, incessant/constructions and deconstructions” (Lee, 1990, p. 25).

\section{Father-Son Relationship and Beyond}

Chin, Chan, Inada, and Wong editors (1974) of Aiiieeeee! claim that

A constant theme in Asian-American literature [...] is the failure of Asian-American manhood to express itself in its simplistic form: fathers and sons [...] The perpetuation of self contempt between father and son is an underlying current in virtually every Asian-American work. (Chin et al., 1974, pp. xlvi-xlvii)

Chin's assertion of the awry relationship between Asian American fathers and sons reflects representations of such a relation in the early Asian American works, but Lee articulates this relationship in a flip-over manner. In both his collections, Lee's relation with his father is enviously conducive and constructive. In Rose, memories of his father and the past have an ability to shape and form his subjectivity. This evolves into an exploration of the relationship between his subjectivity and his own life as an immigrant in the United States. His second collection The City in Which I Love You (Lee, 1990) retains almost all the aesthetic features shown in the first; most poems are lucid, judicious, complex, sometimes obscure, and elastically figurative. They represent a wide range of associative and symbolic narratives, memory, meditations, descriptions, questionings, and exclamations, wherein Lee negotiates his subjectivity more as a Chinese American in a wider social context within the framework of a father-son relationship.

As a refuge, Lee came to America, on his "father's back/in borrowed clothes", initiating the process of "incessant/constructions and deconstructions” of "telling my human/tale, tell it against/the current of that vaster, that/inhuman telling” (Lee, 1990, p. 27). Through the telling he affirms his subjectivity as a Chinese American. This affirmation is well captured in the opening and the concluding poems of his second book, Furious Versions and The Cleaving, respectively. He locates his subjectivity in the diasporic experience of the Chinese immigrants:

America, where in Chicago, Little Chinatown,

who should I see 
on the corner of Argyle and Broadway

but Li Bai and Du Fu, those two

poets of the wanderer's heart. (Lee, 1990, p. 23)

Of all the Chinese American writers, nobody has better recaptured, with as much heart-breaking honesty and sensibility, the tantalizing tension of the historical and cultural discontinuity Chinese American have experienced. Nor has anyone ever uttered with such immediacy the "preemptory of self of the present” (Bhabha, 1994, p. 122). His father and himself are among the wandering hearts: "My father wandered/me beside him, human/erect, unlike roses" (Lee, 1990, p. 23). The phrase "human erect" is reminiscent of the Homo Sapiens, who embarked on a new level of life. For Lee, the new life is not rosy at all because:

I grow more fatherless each day

For years now I have come to conclusions

without my father's help, discovering

on my own what I know, what I don’t know. (Lee, 1990, p. 37)

He lost his father, and needs to rearticulate his subjectivity as a Chinese immigrant. The loss of the father as an image to identify with is virtually compensated by his poetic envisioning of the two ancient Chinese poets $\mathrm{Li}$ Po and Tu Fu, two wandering poets, through whom Lee captures the shadow of his own self. It is through the effort to face the reality of the existence of Chinese Americans that prompts Lee to evoke Li Po and Tu Fu to "meditate on the experience of dispossession and dislocation-psychic and social—which speaks to the condition of the marginalized, the alienated, those who have to live under the surveillance of a sign of identity and fantasy that denies their difference" (Bhabha, 1994, p. 122).

One thing Lee knows now is that in America he finds himself having lost a father but found a community with "my face" (Lee, 1990, p. 77). In The Cleaving, he explores the ethnic physical features as a means to negotiate his subjectivity. The poem begins with Lee's identification with a Chinatown butcher, who "gossips like my grandmother, this man/with my face, and I could stand/amused all afternoon” (1990, p. 77). In the familiar face not only does Lee envisions himself, but all the diasporas, "Such a sorrowful Chinese face/nomad, Gobi, Northern/in its boniness" (Lee, 1990, p. 77). All his emotions and sympathy are registered in the simple exclamation "Such a sorrowful face", on which is write all the imaginable hardships immigrants have endured. The butcher serves for Lee as a grand image of most Chinese Americans, who:

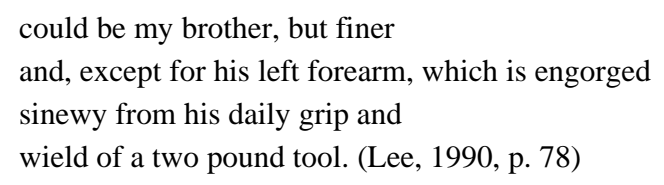

As the poem develops, the motif of cultural displacement is rehashed in beautiful verse. To win the battle of survival, most immigrants have to abandon their own interest and are forced to take low paying jobs and get stuck with them their entire lives. Most of them aim high and think big but end up low in spite of themselves. The old butcher, serving as an epitome of Chinese American cultural displacement, demonstrates this space wart like a floundering whale on the beach: 
moodiness, he is

a Southerner from a river province

suited for scholarship...

He could be my grandfather. (Lee, 1990, p. 78)

Moreover, Lee’s sympathy and love for the immigrant scholar/butcher are extended to all the minority people in the United States in the next section of the poem. Here he challenges the Orientalist notion of racial hierarchy by celebrating the beauty of diversity in physiognomy:

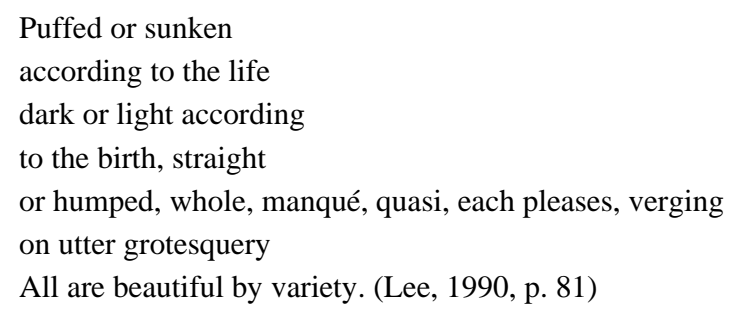

This Chinese immigrant butcher-scholar transcending the limitations of racial politics bears:

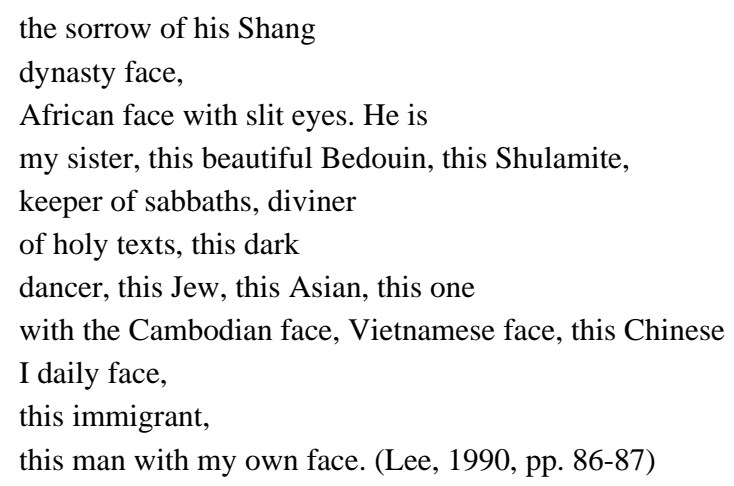

These people are his "[b]rothers and sisters by blood and design[...][who] constitute a many-membered/body of love” (Lee, 1990, p. 81). Noticeably, Lee's celebration and deference for the physiognomic heterogeneity is accompanied by his wish to understand all the immigrants by devouring them, just as he wishes to "eat" his father for the purpose of achieving totality and finality in the understanding of his father:

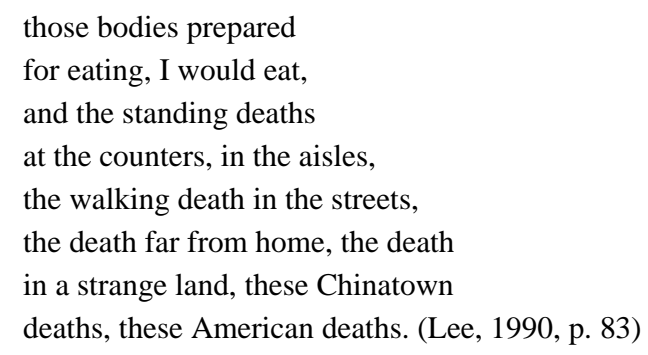

Lee’s "eating [is] a kind of reading” and to "devour the world [is] to utter it” (Lee, 1990, p. 82). Devouring functions as his way of meeting, reading, comprehending, and mastering the world and the unknown by letting the world enter him and reemerge in his poetry in a more comprehensible and manageable manner. Spirituality and subjectivity, as it is, always remain the central concern in Lee's construction of identity, the core of his 
subjectivity. The loss of spirituality due to cultural discontinuity and dislocation constitutes the death of selfhood; hence he only sees "standing deaths", "walking deaths", and "these American deaths". There is nothing surprising if we recall his remarks with Marshall about the relationship between the physical and the spiritual: "The true self is the one that speaks, and it does not give a damn about the one that walks in clothes" (Marshall, 2000, p. 135). Lee's cannibalism designates his wish to restore life to the clothe hangers. Instead of an ogre, "eating" is an act of saving. In this sense, it not only transforms his self but also the world of immigrants, with which he can negotiate his subjectivity in a more comfortably manner and grandeur, because eating serves as a sign of cultural communion that enacts ethnic and diasporic communities.

\section{Conclusion}

As we can see, Lee's attempts (in his first book) to reconstruct his subjectivity by revision as the result of the constant remembrance of what has happened to his family in its incessant, forced relocations, are extended to the celebration of all the ethnic people in the United States in his second book. In the first book, he tries to understand who he is through interpreting, interacting, and memorizing the past, and even tries to "devour" his father in the hope of understanding the godlike man. In the second book, as he enlarges the circle of relationships to include all ethnic people, he tells his "human tale" by writing about the reality of immigration and the consequences of socioeconomics, which impose marginality for not only Chinese Americans but for all the ethnic communities. It is through the medium of remembrance, philosophic meditation, poetic epiphany, and cannibalism that Lee reconstructs his subjectivity. It is through his constant remembering of his father that he enters the world of (Chinese) American immigrants, and understands himself. By utilizing the art of memory of the personal and family histories of cultural reconstruction and re-invention in his interrogations of the question of subjectivity that Lee articulates in his "I" poetry the profundity of the matrix of memory that "revises" him in the arduous process of "putting together of the dismembered past to make sense of the present" (Bhabha, 1994, p. 121). In Rose, Lee's voice is that of an ethnic orphan, who longs to get in, while in The City in Which I Love You, he is much surer as an ethnic hero who transcends borders and boundaries and voices his wishes to hold dialogues with universalism as a fuller, if not "coherent" self. He thenceforth is able to identify with humanity.

\section{References}

Bhabha, H. (1994). Remembering Fanon, self, psyche and the colonial condition. In W. Patrick, \& C. Laura (Eds.), Colonial discourses and post-colonial theory. New York: Columbia UP.

Bhabha, H. (1997). Location of culture. New York: Routledge.

Cavallaro, D. (2001). Critical and cultural theory: Thematic variations. London and New Brunswick: The Athlone Press.

Chang, J. (1996). Reading Asian American poetry. MELUS: The Journal of the Society of the Multi-Ethnic Literature of the United States, 21, 81-98.

Chin, F., Chan, J. P., Inada, L. F., \& Wong, S. (1974). Aiiieeeee!: An anthology of Asian American writers. Washington, D.C.: Howard UP.

Lee, L. Y. (1986). Rose. Brockport: BOA Editions, Ltd.

Lee, L. Y. (1990). The city in which I love you. Brockport: BOA Editions, Ltd.

Marshall, T. (2000). To witness the invisible. Kenyon Review, 22, 129-147.

Yu, T. (2000). Form and identity in language poetry and Asian American poetry. Contemporary Literature, 41, 422-461. 